\title{
EL FUTURO DEL HOMBRE. \\ $¿$ ¿Contienen las propuestas del transhumanismo una respuesta satisfactoria?
}

\author{
Juan Arana. Universidad de Sevilla \\ Real Academia de Ciencias Morales y Políticas, Madrid
}

Resumen: El artículo expone la evolución de las expectativas acerca del futuro y destino final del hombre tanto a nivel individual como colectivo. Hasta el siglo XVIII predominaban las preocupaciones referidas al destino personal de cada hombre y el significado de la muerte. Tras las revoluciones que acabaron con el antiguo régimen, empezó a dominar el interés por el futuro de la humanidad en su conjunto. Desde mediados del siglo XX hay una preocupación creciente ante el peligro de que la especie humana desaparezca y sea suplantada por otro tipo de entidades, tal vez desarrolladas por el propio hombre. El transhumanismo se ha presentado como una respuesta, basada en la ciencia, a las ansias de supervivencia y mejora del hombre. No obstante, sus propuestas adolecen de varias debilidades, algunas de ellas posiblemente irreparables.

Palabras clave: Hombre, futuro, muerte, especie humana, transhumanismo.

The future of man. Do the proposals of transhumanism contain a satisfactory answer?

Abstract: This paper studies the evolution of expectations about the future and final destiny of man at an individual and collective level. Until the 18th century, preoccupations related to the personal destiny of each man and the meaning of death predominated. After the revolutions that ended the old regime, interest in the future of humanity as a whole began to dominate. Since the mid-twentieth century there is growing concern about the danger that the human species will disappear and be supplanted by other types of entities, perhaps developed by man himself. Transhumanism has been presented as a solution, based on science, to the desire for survival and enhancement of man. However, their proposals suffer from several weak points, some of them possibly irreparable.

Keywords: Man, future, death, human species, transhumanism.

Recibido: 22/08/2018 Aprobado: 20/02/2019 
Con cierta brusquedad, se podría plantear la cuestión del futuro del hombre mediante una dicotomía: muerte o inmortalidad. La primera opción es para muchos la más verosímil, pero hay que reconocer que cuesta resignarse a ella. Por eso ha habido y hay varias propuestas que intentan abrirnos el horizonte de la inmortalidad. Dependiendo de donde esté situado éste, podrían distinguirse tres variantes: la transhistórica, la intrahistórica y la posthistórica. La primera de ellas da acceso a la vida perdurable superando los límites de la historia: debemos encontrarla en otra esfera de la realidad, o como mínimo en "unos nuevos tiempos y una nueva tierra". Apuestan por ella las religiones de mayor arraigo y difusión, aunque en los últimos siglos se ha registrado un pronunciado decaimiento del sentimiento que las sustenta. En consecuencia, la modernidad avanzada empezó a proponer una forma de inmortalidad intrahistórica, aunque sólo confiara en alcanzarla de modo problemático y no rescatara de la muerte a los individuos, sino tan solo a la humanidad en su conjunto, o a una parte significativa de ella. Sin embargo, a lo largo del siglo XX, este segundo tipo de esperanza también ha declinado, porque ha cundido por doquier el pesimismo con respecto a nuestra especie y planeta. Para ocupar su hueco, está en pleno auge una tercera vía, la del transhumanismo, que promete supervivencia indefinida tanto individual como colectiva, pero sólo cuando nuestra estirpe haya conseguido transcenderse a sí misma, esto es, cuando el hombre haya culminado su destino histórico, dando lugar a la posthistoria.

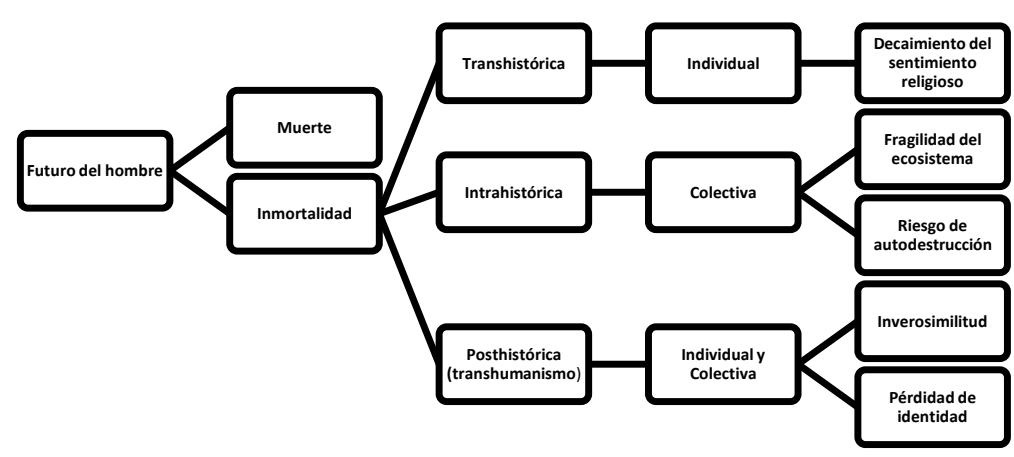


Veamos con mínimo detenimiento cómo se ha producido el tránsito de la segunda a la tercera propuesta para esquivar la muerte. Durante los siglos XIX y XX nuestra especie pareció estar más interesada en su futuro colectivo que en el porvenir particular de cada individuo. Las entidades que debían ser salvadas eran la historia o la humanidad. A partir de la revolución francesa, la preocupación principal de los que defendían grandes ideales se orientaba a establecer las bases de un mundo más justo, mejor administrado, más rectamente encaminado hacia la libertad y el progreso. El auge y despliegue de los nacionalismos obedecía también al propósito de asegurar o culminar el destino de un pueblo, una lengua, una cultura. Las revoluciones socialistas y comunistas perseguían la emancipación ante todo de la clase trabajadora y más a largo plazo de toda la sociedad. En comparación con tan grandiosas metas, poco o nada suponían los desvelos pequeñoburgueses de quienes se inquietaban por sí mismos. En los Manuscritos económicos y filosóficos de 1844, Carlos Marx presentaba la muerte biológica como "una dura victoria del género sobre el individuo" y no tenía nada más que decir al respecto. Sin embargo, la muerte, lo que se dice la muerte, siempre ha sido un acontecimiento privado y cuando se pretende colectivizarlo no deja de ser una redundancia o bien una abstracción. A fuerza de verla repetirse nos hemos acostumbrado a ella (mejor dicho: a la de los demás), y tal vez por esa razón durante mucho tiempo no se consideró un error imperdonable trivializarla. Parte de la culpa hay que achacarla a la teoría de la evolución de Darwin, porque enseñaba que la vida progresa haciendo apuestas con los vivientes. Ganarlas equivale a transmitir las peculiaridades del progenitor a la descendencia; perderlas, morir antes de haber tenido oportunidad de procrear. Por consiguiente, la muerte prematura sería el procedimiento usado por la naturaleza para desembarazarse de sus experimentos fallidos. Todos morimos, pero quienes consiguen engendrar en cierto modo la burlan y eso es —o sería- lo único que importa. El darwinismo social no solo proclamó la insustancialidad de la muerte del individuo, sino que de paso enseñó que es legítimo disponer de ella, sobre todo si es por una buena causa. Así llegamos al siglo XX, cuando reformadores sociales, utopistas y políticos sacaron las 
oportunas consecuencias, de manera que hemos tenido que pagar con usura los errores de nuestros bisabuelos. Como afirma en uno de sus escolios el pensador colombiano Nicolás Gómez Dávila: "Ningún siglo anterior presenció tantas matanzas en nombre de tan transparentes imposturas" (NEII, 121e). La decepción generada por las dos conflagraciones mundiales y su enorme pero sobre todo inútil costo en sangre y sufrimiento, motivó que poco a poco se disiparan los espejismos que habían dado lugar a tales derroches. La revolución de mayo del 68 y la proliferación de movimientos pacifistas señalaron el principio del fin de las ideologías. Pero si los principales enemigos de la vida humana en su individual encarnación acabaron por desaparecer del escenario de la historia, no se restablecieron los fueros de la vida humana individual. Seguimos despreciando la del prójimo; la única diferencia es que ya no buscamos una coartada moral para suprimirla: acabamos con ella gratuita y arbitrariamente, tal como vemos día a día virtualmente en películas, videojuegos o series de televisión y realmente en ataques terroristas $\mathrm{u}$ homicidios que abarcan todo el espectro de la biografía, desde que somos concebidos hasta nuestra natural consunción.

Sin embargo, y como supuestamente dijo Galileo en ocasión memorable: eppur si muove: nuestra entrañas se conmocionan ante el espectáculo de cualquier muerte. Obscura o lúcidamente nos damos cuenta de que, con cada hombre y cada mujer, por extraños y remotos que sean, somos nosotros mismos los que morimos. Al llorar por ellos barruntamos nuestro propio duelo. No se trata de rechazar la condición de mortal en sí misma, ya que sería por completo estéril. Como dice la sabiduría popular: "donde va el cuerpo, va la muerte". Lo que provoca legítimo rechazo es la pretensión de que tenga la última y definitiva palabra, que no haya otra respuesta a la eterna e inquietante pregunta, que se quite al hecho cualquier significado. Hay muchos que pretendieron y siguen pretendiendo reconciliar del todo al hombre con su condición de mortal. Borges, por ejemplo, dedicó a esa aspiración unos versos memorables:

iAh, si aquel otro despertar, la muerte,

Me deparara un tiempo sin memoria 
De mi nombre y de todo lo que he sido!

iAh, si en esa mañana hubiera olvido!!

En otro lugar afirma tajante:

Quiero morir del todo; quiero morir con este compañero, mi cuerpo².

La voluntad gusta a menudo de remar contra la corriente. Pero lo cierto es que la afirmación de la vida se impone al capricho eutanásico, incluso en la circunstancia más extrema. Como apunta el propio Borges:

El hombre ha muerto.

La barba no lo sabe.

Crecen las uñas ${ }^{3}$.

En la cultura de hoy se detecta un doble movimiento: por un lado la muerte se trivializa haciéndola algo cotidiano e intrascendente. Una vez más me serviré de un ficticio diálogo de Borges consigo mismo para ilustrar esta tendencia:

[Interlocutor $1^{\circ}$ :] Con una indiferencia y una dulzura más convincentes que el fervor, Macedonio Fernández repetía que el alma es inmortal. Me aseguraba que la muerte del cuerpo es del todo insignificante y que morirse tiene que ser el hecho más nulo que puede sucederle a un hombre. [...] Un acordeón vecino despachaba infinitamente La Cumparsita [...] Yo le propuse a Macedonio que nos suicidáramos, para discutir sin estorbo. [Interlocutor $2^{\circ}$ :] Pero sospecho que al final no se resolvieron. [Interlocutor $1^{\circ}$ :] Francamente no recuerdo si esa noche nos suicidamos ${ }^{4}$.

${ }^{1}$ Jorge Luis Borges, El otro, el mismo (1964), Obras completas, Barcelona, Emecé, 1989, vol. 2, p. 272.

${ }^{2}$ Jorge Luis Borges, Elogio de la sombra (1969), Obras completas, Barcelona, Emecé, 1989, vol. 2, p. 392.

${ }^{3}$ Jorge Luis Borges, La cifra (1981), Obras completas, Barcelona, Emecé, 1989, vol. 2, p. 392.

${ }^{4}$ Jorge Luis Borges, El Hacedor, Obras completas, Barcelona, RBA, 2005, I, p.784. 
La otra cara de la moneda está en el horrendo pavor que un hecho tan inesquivable genera. Oscilamos entre la trivialización y el negacionismo. Resulta chocante cómo se maquilla y disimula todo lo relativo a ella cuando de verdad acecha, para que pase lo más desapercibida posible y parezca como que no existe. En suma: omnipresencia de la muerte ficticia y escamoteamiento de la muerte real.

Con todo, resulta evidente que, ficcionalizada o escamoteada, el interés por ella ha aumentado mucho en los últimos decenios. No se conocía algo así desde la moda existencialista de la postguerra. Quizá se deba al descubrimiento de que la muerte no siempre afecta tan solo a los individuos. Desde tiempo atrás se conocía el fenómeno de la extinción de las especies biológicas, pero la paleontología descubrió más tarde episodios de extinciones en masa, algo que, lejos de resultar insólito, se repite con frecuencia y sigue ciertos patrones. El choque de grandes meteoritos, variaciones en los ciclos climáticos, catástrofes volcánicas de gran intensidad, la deriva de los continentes y quién sabe cuántas causas naturales más acaban fácilmente con partes significativas de la biosfera. Nosotros podríamos estar en la lista de futuros damnificados. La novedad aportada por la ciencia y la técnica es que abre la puerta a una versión artificial del fenómeno: desde que se averiguó cómo liberar las ingentes cantidades de energía encerradas dentro del átomo, la eventualidad de que toda la progenie humana arda en un holocausto nuclear no es remota. Durante decenios era la amenaza más inmediata que nos acuciaba, y aunque ha dejado de ser una preocupación omnipresente es probable que a corto, medio o largo plazo siga siendo el peligro más real y difícil de sortear. A este propósito, con alguna frecuencia se ha hecho la siguiente consideración: el universo es suficientemente grande y antiguo para haber alumbrado civilizaciones mucho más avanzadas que la nuestra en gran cantidad de lugares. Aunque los planetas habitables están separados por distancias enormes, el progreso tecnológico debiera haber podido vencer la lejanía y nosotros tendríamos que haber recibido hace mucho tiempo la visita de vecinos más evolucionados. ¿Por qué no lo han 
hecho? Acaso, porque antes de estar en situación de colonizar amplias zonas de la galaxia, todas las culturas que han medrado han tenido - y aprovechado- la oportunidad de autodestruirse. Ojalá que el motivo haya sido otro y sobre todo ojalá que nosotros no sigamos un sendero tan lamentable.

Dejando a un lado la cuestión de qué proporción de realidad y de vacua especulación hay en todo esto, lo cierto es que en el imaginario colectivo la muerte ha dejado de ser un problema que afecte tan sólo a los individuos: alcanza o puede alcanzar también a los colectivos y al propio planeta, tal como con ejemplar insistencia nos adoctrinan los más pesimistas portavoces del ecologismo. Que la Tierra ha de morir, por otro lado, es algo más que una hipótesis. El encuentro con cuerpos siderales capaces al menos de acabar con parte o toda la vida que hay en ella es un acontecimiento infrecuente, pero previsible y a la larga ineludible. Bien es cierto que si nuestras habilidades ingenieriles siguen avanzando, tal vez seamos capaces de prever este tipo de colisiones con suficiente antelación y actuar con presteza para conjurarlas. Mucho más difícil será evitar que, cuando consuma la mayor parte de su combustible nuclear, el sol se convierta en una estrella gigante roja y nos abrase. Bien es verdad que la catástrofe es lejana. Me contaron a modo de chiste que un conferenciante anunció a su auditorio que este apocalipsis tendrá lugar dentro de seis mil millones de años. “¿Cuándo ha dicho?”, preguntó ansiosa una voz desde la última fila. "Dentro de seis mil millones de años..." "iAh bueno — repuso aliviada—. Le había entendido que eso iba a ser dentro de seis millones de años nada más..." A mí particularmente ambas moratorias me parecen igualmente tranquilizadoras, aunque puede haber - y no solo como chiste- quien considere que la primera es demasiado exigua. Podemos avanzar estimaciones muy variadas relativas a las posibilidades de que ocurran deterioros irreversibles del clima o de la atmósfera, la contaminación de tierras y mares, el encuentro con cometas y meteoritos, conflagraciones nucleares o bioquímicas, el agotamiento del sol o desembarcos hostiles procedentes de otros mundos. En todo caso carece de sentido buscar consuelo a la mortalidad individual en la más que problemática inmortalidad colectiva. Aunque haya 
una diferencia de escalas, la muerte nos acecha tanto en una perspectiva como en otra. $\mathrm{O}$ renunciamos de una vez por todas a la esperanza de vencerla en ninguna de las versiones, como proponían los textos borgesianos que poco antes he citado, o habría que buscar una salida diferente. Los metafísicos han barajado, por ejemplo, la idea del eterno retorno o la metempsicosis. La religión ofrece otra solución, y he de añadir que es la única que personalmente me convence. Pero no he venido a hablarles de mis propias creencias, sino de la posibilidad de procurarnos un futuro invulnerable hic et nunc, aquí y ahora, o por lo menos en algún lugar accesible del espaciotiempo, y en todo caso sin la mediación de instancias sobrenaturales. Tal es, en efecto, la fórmula que propone el transhumanismo.

No todos los autores y escuelas comprometidos en esa corriente tienen pretensiones tan desmesuradas como la que acabo de referir. Pero es en ellos donde el mordiente de la escuela resulta llamativo. Prácticamente todos confiamos en que el progreso del conocimiento y de la técnica seguirá solucionando problemas y remediando necesidades como innumerables veces lo ha hecho en el pasado. Cada día nos sorprende con nuevas proezas y en algunos ámbitos, como en el de las comunicaciones, a un ritmo prodigioso. ¿En qué se diferencia, entonces, el transhumanismo de los simples partidarios del progreso tecnocientífico? Precisamente en su pretensión de convertir la tecnociencia en una especie de solucionador universal autosuficiente. Hay un segundo rasgo que lo caracteriza: hasta hace poco se distinguía entre los remedios y quienes resultaban favorecidos por ellos. El hombre seguía siendo hombre; los remedios, remedios. Ahora en cambio las soluciones amenazan con suplantar la identidad de sus supuestos beneficiarios.

Cuando todavía se acostumbraba a llevar los aparatos estropeados a arreglar, a veces el operario explicaba que la reparación no merecía la pena y que resultaba preferible tirar a la basura todo el dispositivo y comprar otro nuevo. La prudencia del propietario y la honestidad del profesional dirimían la cuestión en orden a encontrar la resolución más aconsejable. Por cierto que eso también ocurría con nuestros propios organismos. Una tía mía que 
había sobrevivido a un cáncer me comentó en cierta ocasión: "Voy a ir al oncólogo a que me revise antes de arreglarme la dentadura; a lo mejor no trae cuenta..." (Dicho sea entre paréntesis, vivió 30 años más y gastó, no una, sino dos dentaduras postizas más). Muchos ancianos se niegan a operarse de esto o de revisar aquello con la comprensible razón de que ya se sienten "amortizados", sin que por ello sea legítimo considerarlos desertores de la vida. La capacidad de hacer "cosas" para mejorarnos no es una opción carente de límites o restricciones. El concepto de "ensañamiento terapéutico" está en la mente de todos. Los que ya tenemos cierta edad recordamos el final del general Franco y el exceso de celo que mostró el equipo encargado de atenderlo. Por eso quién más, quién menos, todos hemos dejado dicho a nuestros más próximos: "llegado el momento que la prudencia aconseje, dejadme morir tranquilo, por favor." De hecho, la profesión médica no se lo plantea ya de otra manera y ha desarrollado el concepto de "cuidados paliativos", sin que lo hayamos satanizado con un aura siniestra. Pero lo que ahora se plantea no es la desaparición del individuo, sino de la especie. Algunos insinúan y otros afirman que las cintas de las mejoras tecnológicas valen ya, o valdrán dentro de poco, más que el manto del homo sapiens que teóricamente deberían adornar.

No dispongo de espacio ni capacidad de análisis suficiente para ofrecer una panorámica completa del movimiento transhumanista. Por eso voy a mencionar tan solo unos pocos nombres y centraré mi atención en uno de sus más destacados representantes: Ray Kurzweil, destacadísimo inventor y experto en inteligencia artificial, que ha sido pionero en las técnicas de OCR, escaneado, síntesis de texto a voz, etc., etc. Interesa particularmente en este momento por ser autor de una serie de libros, entre ellos La era de las máquinas inteligentes (1987-1988), La era de las máquinas espirituales, cuando los ordenadores superen la mente humana (1999), ¿̇Somos máquinas espirituales? (2002), Cómo crear una mente (2012), sobre todo, La Singularidad está cerca (2005), que constituye un auténtico manifiesto para muchos partidarios de la causa. La que más sobresale entre las muchas y muy atrevidas ideas de Kurzweil es la tesis de que es posible transcender el hombre sin arruinar su 
identidad. Dicho paradójicamente, defiende que podremos seguir siendo humanos tras dejar de serlo. Y, en lo que respecta al tema de la inmortalidad, defiende la nada habitual postura de que es alcanzable tanto en el plano colectivo como individual. De hecho aspira a ser él mismo uno de los primeros especímenes del género humano que venza a la muerte, y en absoluto se trata de una broma, sino una tarea en la que está comprometido de lleno:

Estos resultados no son accidentales, ya que he sido muy agresivo a la hora de reprogramar mi bioquímica. Diariamente, tomo 250 suplementos (en forma de píldoras) y recibo media docena de terapias intravenosas a la semana (básicamente suplementos nutricionales inyectados directamente en mi torrente sanguíneo para evitar mi tracto gastrointestinal). En consecuencia, las reacciones metabólicas de mi cuerpo son completamente diferentes de lo que serían sin estos tratamientos. $\mathrm{Al}$ abordar esto como ingeniero, me controlo los niveles de docenas de nutrientes (tales como vitaminas, minerales y grasas), de hormonas y de derivados metabólicos que se encuentran en mi sangre y en otras muestras como el pelo y la saliva. En general, mis niveles están donde quiero que estén, aunque continuamente reajusto mi programa... ${ }^{5}$

Dejando a un lado su particular batalla por la supervivencia - en la que le deseo mucho éxito-, por lo que se refiere a la de toda la especie cree que la victoria vendrá de la mano de los progresos en tres frentes: bioquímica, inteligencia artificial y nanotecnología. Por asombrosos que sean los resultados cosechados en todos ellos, parece (y no solo a primera vista) que el empeño elegido es excesivo. Por mi parte empezaré a creer en las posibilidades de la ciencia para prolongar significativamente la vida cuando haya conseguido resolver de verdad problemas en apariencia mucho más sencillos como la calvicie o las varices. Pero Kurzweil confía en un talismán con el que espera hacer caer todas las barreras: la ley de los rendimientos acelerados, que - y perdonen la vulgaridad de la expresión — representa algo así como el cuento de la lechera del progreso tecnológico:

${ }^{5}$ Ray Kurzweil, La singularidad está cerca. Cuando los humanos transcendamos la biología, Berlin, Lola Books, 2012, p. 237. 
¿Puede el ritmo del progreso tecnológico continuar acelerándose indefinidamente? ¿no hay un punto a partir del cual los humanos no somos capaces de pensar lo suficientemente deprisa como para mantener el ritmo? Ciertamente esto es así para humanos no mejorados, ¿̇ero qué no conseguirían mil científicos, cada uno mil veces más inteligentes que los científicos humanos de hoy, funcionando cada uno mil veces más deprisa que los humanos actuales (porque el procesamiento de información es más veloz en sus cerebros en su mayor parte no biológicos)? Un año cronológico sería como un milenio para ellos. ¿Qué no inventarían?6

Todos conocemos la historia del individuo que como premio a sus servicios pidió un grano de arroz en la primera casilla de un tablero de ajedrez, dos en la segunda, cuatro en la tercera y así sucesivamente. Resulta que no hay arroz en el mundo suficiente para rellenar las 64. Algo semejante ocurriría en el presente caso: la capacidad resolutiva de esta revolución cognitiva que Kurzweil anuncia resolverá muchos más problemas de los somos capaces de imaginar. No está mal como promesa, pero tratemos de situar el asunto en un contexto más amplio.

La perspectiva del enhancement o mejora cambia bastante cuando la abordamos desde la perspectiva del individuo o de la especie. Casi todos estaremos de acuerdo en que es preferible un cuerpo sano y fuerte a otro débil y enfermizo. Pocos negarán que sea mejor una mente despierta y bien adiestrada que otra somnolienta y torpe. La pregunta es cuánto cuesta cada mejora en términos de esfuerzo y renuncia a otras posibilidades incompatibles con su adquisición. La publicidad nos apremia continuamente hasta el atosigamiento, y hay mil formas aún más sutiles de ponernos en el disparadero de iniciar una espiral de cambios y "mejoras" que tal vez sea difícil luego controlar e imposible detener. Eso por lo que se refiere a cada uno de nosotros. El problema se agudiza porque nadie vive ensimismado y como encerrado en una urna de cristal. El que se da a la bebida o se aficiona al

${ }^{6}$ Kurzweil, La singularidad está cerca, p. 27. 
juego no sólo arruina su vida, sino que pone en apuros a los allegados y a veces incluso a personas que nada tenían que ver. Supongamos que antes de traer hijos al mundo me proponen la posibilidad de efectuar un cambio irreversible en mis genes. ¿'Tengo derecho a tomar esa decisión, sabiendo que van a pasar a mis descendientes, y que si lo hago por consideraciones egoístas o simplemente circunstanciales conseguiré que ellos se acuerden - y no para bien- de su antepasado? Otro caso es el de artistas y otros devotos de la imagen que, a fuerza de intervenciones quirúrgicas y tratamientos variados para mejorar su aspecto, acaban convertidos en monstruos o por lo menos resultan irreconocibles. Por lo menos estas gentes sólo se juegan su propio pellejo, pero, ¿qué pasaría si al hacernos un tatuaje que ocupe el $100 \%$ de la epidermis condenásemos a todos nuestros descendientes a seguir llevándolo por los siglos de los siglos? Es verdad que no soy muy partidario de este tipo de prácticas, pero, aunque fuese devoto de ellas, consideraría inadmisible decidir de una sola vez por todos los que vienen detrás.

El asunto, por consiguiente, cambia de naturaleza cuando compromete la identidad de quienes no participan en las decisiones que acaban afectándoles. Poco a poco hemos ido tomando conciencia de que el planeta que habitamos no es nuestro, sino que sólo somos sus inquilinos, con derecho de uso pero no de abuso. Reconocemos y asumimos la seria obligación de no estropearlo ni convertirlo en un medio hostil a la vida tal como la conocemos. Pero todavía nos cuesta darnos cuenta de que, en contra de lo que proclaman algunas ideologías de combate, tampoco son de propiedad privada nuestros cuerpos, y muy en particular no lo son las partes de ellos más directamente relacionadas con la reproducción. Y eso por consideraciones escuetamente biológicas: compartimos un patrimonio genético, del que a cada individuo y generación corresponde una parte alícuota muy pequeña. El orden reinante en el universo ha establecido varios mecanismos para administrar ese patrimonio. La selección natural es uno de ellos, aunque sin duda no el único. En el caso de la especie humana (y de muchas otras) la 
cultura ha establecido unos correctivos importantes a la dinámica que anteriormente determinaba la identidad genética de los vivientes. Ahora bien: en los últimos tiempos la cultura adolece de hipertrofia en alguna de sus partes (ciencia, técnica) y debilitamiento en otras (ética, política, religión). Diríase incluso que la motivación ha decaído, puesto que, cuando se creía que la humanidad era imperecedera, abundaban los que estaban dispuestos a sacrificarse por su futuro; ahora que la sabemos amenazada titubeamos antes de asumir costos importantes en su provecho. Es como si exigiéramos la pronta devolución de créditos que antes habíamos otorgado con liberalidad. En la película de Stanley Kubrick ¿̇Teléfono rojo? Volamos hacia Moscú hay un adelanto de este cambio de actitud: los máximos dirigentes de la política, el ejército y la ciencia descubren en un momento dado que no hay modo de evitar la guerra atómica que ha provocado un desequilibrado. En lugar de intentar maniobras de última hora para salvar al género humano, se apresuran a evadirse, abandonando por una puerta falsa el buque que se hunde. Dan por hecho que serán ellos mismos los únicos supervivientes; identifican con descarado egoísmo el futuro del hombre con su propio porvenir. Asumen la cínica divisa: "Sobreviva yo y perezca el mundo". La historia del Arca de Noé ha tenido muchos imitadores durante el último siglo. Hay versiones de ella hasta en el cómic: Supermán, primer y principal héroe del imaginario contemporáneo es el único de su raza que consiguió hurtarse a la destrucción del planeta originario, Krypton. De allí llegó a la Tierra para favorecernos con superpoderes que no tienen otro paradójico antídoto que cualquier pedacito de su tierra natal, la kryptonita.

Así pues, la óptica soteriológica sigue en pie, pero los términos se invierten: antes eran los individuos los que se inmolaban ante el altar de la humanidad futura; ahora el propio género humano carece de futuro, anonadado por problemas irresolubles que él mismo ha suscitado jugando a ser aprendiz de brujo. Pero sigue sin escarmentar: para completar la inversión, será la vieja humanidad la que se sacrificará para alumbrar a quienes hayan de conocer los nuevos tiempos. Uno de los que pronosticaron este escenario 
con mayor entusiasmo fue Marvin Minsky, el recientemente fallecido y destacado adelantado de la inteligencia artificial. Publicó en Scientific American hará un cuarto de siglo un artículo con el provocativo título: ¿Serán los robots quienes hereden la Tierra? No había que esperar mucho para averiguar su respuesta, ya que el subtítulo rezaba: Así será, pues la nanotecnología permitirá crear cuerpos y cerebros de repuesto. Entonces viviremos más, poseeremos mayor sabiduría y gozaremos de facultades inimaginadas. Lo que más sorprende de su propuesta es la utilización de la primera persona del plural para designar nuestros hipotéticos sustitutos. Aquí late, indudablemente, un problema de identidad; pero sería injusto decir que el autor no se siente capaz de afrontarlo. Afirma que en el momento presente el conocimiento no progresa mucho, debido a la gran lentitud de nuestros cerebros. Pronostica que a medida que se vaya conociendo el funcionamiento de los subsistemas cerebrales, los reproduciremos y realizaremos prótesis que insertaremos en nuestra mente mediante interfaces electroquímicas. Al final, reemplazaremos todas las partes del cuerpo y del cerebro y así superaremos nuestras limitaciones. Superfluo decir que con ello estaremos convirtiéndonos en máquinas. ¿Significa eso que seremos reemplazados por dispositivos inteligentes? Minsky aseveraba que no tiene sentido enfocar la cuestión en términos de "ellos" y "nosotros". Por eso se suma a otro de los pioneros del movimiento transhumanista, Hans Moravec, quien propone considerar a los robots que nos sucedan como nuestros "hijos mentales".

Permitan que interrumpa el hilo de mi exposición para aconsejarles que acojan las discusiones que estoy relatando con la máxima paciencia y serenidad. Conviene mantener la cabeza muy fría y no caer en la tentación de mandar directamente a la porra propuestas tan extravagantes, porque, para bien o para mal, eso es lo que hay y son muchos, tal vez demasiados, los que no solamente las toman en serio, sino que se disponen a propiciarlas con todas sus fuerzas.

Aunque el debate sobre el transhumanismo suele plantearse dentro del horizonte de lo que la ciencia presente y futura hace o hará posible, lo cierto es que involucra conceptos que se adentran en el terreno de la antropología 
filosófica y aún de la metafísica. Porque saber si podremos compartir las conjugaciones verbales (yo, tú, nosotros, etc.) con máquinas o entidades de dudoso origen no se pude dilucidar sin aclarar los conceptos de especie, esencia, continuidad, e identidad. Mejorar la especie implica suprimir o cuando menos aminorar defectos y aumentar, incluso añadir virtudes. Al hacerlo modificamos evidentemente nuestra condición; ¿lo haremos hasta el punto de que ya no sea lícito seguir considerando humanas las criaturas resultantes? En otras palabras, ¿̇retendremos nuestra identidad indefinidamente, sean cuales sean las innovaciones que se introduzcan en nosotros mismos y en nuestros descendientes? La respuesta convencional es que la identidad de un sujeto y también la de un colectivo se mantienen mientras los cambios sean accidentales, no esenciales. iPero si decimos eso habremos pronunciado una palabra que muchos quisieran prohibir! iNada menos que la esencia! ¿Hay algo en el mundo real que responda a tan denostado término? Mucho me temo que mientras usemos las mismas palabras para referirnos a cosas diversas, si no queremos admitir las definiciones o esencias, tendremos que introducir subrepticiamente nociones equiparables. ¿Seguirá siendo humano un vástago al que hayamos añadido dos brazos suplementarios, un tercer ojo en el occipucio, un radar en medio de la frente, pequeños turborreactores debajo de los pies y un par de discos duros dentro del cráneo? Lo más probable es que el sentido de la estética proteste antes que la inteligencia. Para doblegar la resistencia de los que se niegan a meter en el mismo cesto seres a todas luces diferentes, los transhumanistas solicitan la ayuda de la biología de la evolución e invocan como arma decisiva la idea de continuidad: si hay una gradación de formas intermedias entre las que cualquiera solo reconocería diferencias accidentales, al final sólo puede haber eso: acumulación de accidentes; nunca cambios sustanciales, aparición de nuevas esencias o desaparición de las antiguas. Bien es verdad que admitir este criterio nos hermanaría con las amebas y las orquídeas: todos formaríamos parte de una única especie viviente, con variaciones grotescas, pero insustanciales. Se dice que Pitágoras reconoció a un pariente en un perro al que apaleaban y prohibía consumir habas para no correr el peligro de devorar 
el alma de un semejante. Por esta senda llegamos muy pronto a paradojas tan inadmisibles, que al final resulta preferible resucitar las esencias a pesar de todos sus inconvenientes.

Vean cómo nos hemos embarcado en una pequeña indagación filosófica y cuán pronto hemos llegado a un callejón sin salida. Los transhumanistas son pragmáticos y prefieren escenarios que, aun siendo puramente hipotéticos, servirían para despejar cualquier duda por la vía de los hechos. Hans Moravec, autor más arriba mentado, propone hacerlo conjeturando una situación —conviene recordarlo- de pura ciencia-ficción. Perdónenme que introduzca una larga cita para exponerla:

Le acaban de meter en un quirófano. [...] Usted tiene a su lado un ordenador que espera convertirse en un equivalente humano. Lo único que le falta para empezar a funcionar es un programa. Le anestesian el cráneo, pero no el cerebro. Usted está totalmente consciente. El robot cirujano le abre el cráneo [...] Los instrumentos $[\ldots]$ examinan los primeros milímetros de la superficie del cerebro. $[\ldots]$ Estas medidas [...] le permiten al cirujano escribir un programa que modele el comportamiento de la capa superior del tejido cerebral examinado. Se instala el programa en una pequeña porción del ordenador que está esperando y se activa. [...] Para que a usted no le quepa ninguna duda sobre la exactitud de la simulación, tiene un botón que puede pulsar si desea comparar por sí mismo la simulación con el funcionamiento del tejido original. [...] Usted aprieta el botón, lo suelta y lo vuelve a apretar. No siente ninguna diferencia. En cuanto usted queda satisfecho, se establece permanentemente la conexión de la simulación. [...] Se repite el proceso en la capa siguiente y en seguida aparece una segunda simulación en el ordenador, que se comunica con la primera y con el resto del tejido cerebral original. A medida que avanza el proceso, se va simulando y excavando en el cerebro, capa tras capa. Finalmente, su cráneo se queda vacío [...] Aunque usted no ha perdido la conciencia, ni siquiera el hilo de sus pensamientos, su mente ha pasado de su cerebro a una máquina. [...] Su cuerpo, repentinamente abandonado, sufre algunos espasmos y muere. Durante un momento, lo único que experimenta usted es quietud y oscuridad. Y, de nuevo, puede abrir los ojos. Pero ahora su perspectiva ha cambiado. La 
simulación del ordenador [...] se ha conectado con un cuerpo nuevo y brillante, del estilo y color que usted había elegido. Su metamorfosis ha terminado ${ }^{7}$.

Ocioso añadir que lo que aquí se cuenta es perfectamente inverosímil, pero ahora no es prioritario impugnar la pretensión de que algún día llegue a ser realizable, sino advertir que — de serlo— plasmaría una vieja idea en la que reincidieron filosofías y religiones de la antigüedad: la transmigración de las almas, de manera que nuestro yo se desprendería del acostumbrado asiento biológico en el cerebro, para incardinarse en un sofisticado cúmulo de circuitos electrónicos. Es una versión futurista del viejo dualismo, una de las concepciones filosóficas más criticadas por el materialismo de todas las épocas. Éste siempre insistía en que no existen dos clases de sustancias, sino una sola, la materia, siendo el espíritu tan solo un aspecto marginal de su comportamiento. Lo chocante es que los transhumanistas de hoy quieren prolongar a su manera el materialismo de ayer, pero no dejan de considerar que la mente es en último término información, y que como tal puede ser desprendida de su soporte material y trasladada a otro basamento, en lo cual cifran las posibilidades de mejora y supervivencia. Por eso abunda el transhumanismo más entre los que se dedican a la inteligencia artificial que entre los neurocientíficos, porque éstos últimos insisten una y otra vez en las profundísimas diferencias que hay entre el funcionamiento del cerebro y el de cualquier ordenador. Diré que la propuesta de los informáticos es desde luego bastante más simplista, pero también más diáfana, mientras que la de los biólogos es probablemente más realista, pero notoriamente confusa. Así pues me ceñiré a la primera para señalar que no consigue resolver el problema de la identidad personal ni siquiera en principio. Y no lo consigue, precisamente porque la transferencia que proponen podría repetirse a voluntad, es decir, se podría clonar muchas veces el mismo sujeto, y resolver de paso el problema de la multilocación: una copia de nuestro yo se quedaría trabajando, mientras otra saldría de paseo con los amigos y así sucesivamente. ¿O no? El matemático Roger Penrose ha advertido que se

${ }^{7}$ Hans Moravec, El hombre mecánico, Barcelona, Salvat, 1993, pp. 130-132. 
podría recurrir al mismo procedimiento para efectuar teleportaciones, y en consecuencia darse situaciones tan truculentas como la siguiente:

¿Qué sucedería si la copia original del viajero no fuera destruida, como requieren las reglas del juego? ¿Estaría su "consciencia" en dos lugares a la vez? Trate de imaginar su respuesta cuando le dicen lo siguiente: "iOh Dios mío!, ¿̇de modo que el efecto de la droga que le suministramos antes de colocarle en el teleportador ha desaparecido prematuramente? Esto es un poco desafortunado, pero no importa. De todos modos le gustará saber que el otro usted —ejem, quiero decir el usted real, esto es - ha llegado a salvo a Venus, de modo que podemos, ejem, disponer de usted —ejem—, quiero decir de la copia redundante que hay aquí. Será, por supuesto, totalmente indoloro..." ${ }^{8}$

La historieta sirve para desenmascarar la falacia con que operan muchos transhumanistas: para conseguir hacer de la mente humana algo transferible de un soporte a otro hay que convertirla en un programa informático, es decir, en una secuencia finita de instrucciones inequívocas. Es lo que en la jerga de la profesión se denomina un algoritmo. Conviene advertir que cualquier algoritmo, no importa lo largo y complicado que sea, es algo anónimo, una cosa. Ahora bien, toda cosa es un ello, no hay modo de convertirla en un yo. Los "ellos" son realidades objetivas, exhaustivamente diseccionables; no esconden misterios imposibles de sondear. En cambio los yos son realidades subjetivas, personales e intransferibles, que están fuera del alcance de no importa qué cirujano del cerebro o ingenio teleportador. Por lo tanto, si algún día llega a ensayarse en serio este tipo de experiencias, sin lugar a dudas se desecharía el niño junto con el agua en que lo han bañado. La conciencia que hay dentro de cada ser humano es una lucecita muy tenue y frágil, pero no es del tipo de las que saltan haciendo entrechocar dos pedernales. Precisa del cerebro para seguir encendida, y de un cerebro en buenas condiciones, mas todo lo que la ciencia ha averiguado o puede llegar a averiguar en el futuro es insuficiente para explicar el cómo y el porqué de su

${ }^{8}$ Roger Penrose, La nueva mente del emperador, Madrid, Mondadori, 1991, p. 54. 
leve resplandor. Lo curioso del caso es que los científicos más sagaces — por muy materialistas que sean- lo saben perfectamente. Oigan lo que dice el premio Nobel Gerald Edelman a este propósito:

¿En virtud de qué misteriosa transformación el disparo de las neuronas de un lugar particular del cerebro o de las dotadas de una propiedad bioquímica particular se convierte en experiencia subjetiva, pero no así el disparo de otras neuronas? No es de extrañar que algunos filósofos vean en estos intentos un excelente ejemplo de un error categórico: el error de atribuir a las cosas propiedades que no pueden tener'.

De todos modos, no es lo mismo detectar un error que evitarlo. Los adeptos al transhumanismo, como los restantes partidarios de dar a todo una explicación "natural", siguen creyendo que algún inverosímil salto mortal de la materia interactuando o de la información transitando de aquí para allá producirá el "más difícil todavía" de alumbrar una conciencia. Y como el fin que persiguen se les resiste, optan por lo más fácil, o sea: convertir el fenómeno en una simple reverberación, un espejismo, en definitiva: una nada. Solo así se entiende que les parezca perfectamente plausible hacer "copias de seguridad" de uno mismo, como taxativamente adelanta Kurzweil:

A medida que nos acerquemos a una existencia no biológica, iremos alcanzando los medios para "hacer copias de seguridad de nosotros mismos" (almacenar los patrones fundamentales subyacentes de nuestros conocimientos, capacidades y personalidad), y así eliminaremos la mayoría de las causas de la muerte tal y como la conocemos ${ }^{10}$.

Todos los que bregamos con ordenadores y archivos informáticos sabemos que el peligro de hacer demasiadas "copias de seguridad" es que uno

\footnotetext{
${ }^{9}$ Gerald M. Edelman, Giulio Tononi, El universo de la conciencia. Cómo la materia se convierte en imaginación, Barcelona, Crítica, 2002, p. 21.

${ }^{10}$ Kurzweil, La singularidad está cerca, p. 370.
} 
acaba confundiendo las copias más atrasadas con las más recientes, y envía al editor no la última, sino alguna de las penúltimas versiones del texto que quiere publicar. Peor todavía es darse cuenta de que uno ha estado trabajando paralelamente sobre dos versiones diferentes, de manera que ha generado distintas variantes, ninguna de las cuales es "la genuina". Si trasladamos la metáfora al caso de la identidad, ¿dónde estará de verdad mi propio yo? ¿Acaso me escindiré en una pluralidad de sujetos cada uno de los cuales pretenderá ser el legítimo? Si alguna vez llega a plantearse la cuestión, no tengo duda alguna sobre la respuesta: ninguno. En algún punto del recorrido que fusione el animal humano con la máquina se habrá producido la pérdida del yo; en modo alguno estaré entre los restos de mi naufragio. Más que inquietante, resulta triste comprobar la incapacidad de los transhumanistas para percibir una evidencia tan clara. Una vez más Kurzweil tiene el privilegio de no caer en necios disimulos. Para él seguiremos siendo humanos, porque seremos o serán racionales nuestros futuros avatares. $\mathrm{Mu}$ cho más problemático será conservar la animalidad, porque de lo que se trata, en definitiva, es de trascender la biología:

Nuestra fusión con nuestra tecnología puede llevarnos a resbalar hacia abajo por una pendiente resbaladiza, pero también a deslizarnos hacia la promesa de algo superior, no hacia abajo donde se encuentra el abismo nietzscheano. Algunos analistas se refieren a esta fusión como a la creación de una nueva "especie". Sin embargo, la idea de especie es un concepto completamente biológico, mientras que lo que estamos haciendo es transcender la biología ${ }^{11}$.

Etimológicamente "transcender" implica ir más allá de lo que se trasciende, pero implícitamente se entiende que ese más allá esta "más alto" y no "más bajo". Sin embargo, los transhumanistas proponen una salida de nosotros mismos que en cierto modo es regresiva, puesto que aquello en cuya dirección quieren movernos es precisamente "la máquina":

${ }^{11}$ Kurzweil, La singularidad está cerca, p. 429. 
...tenemos suficiente poder de abstracción para hacer afirmaciones razonables sobre la naturaleza de la vida después de la Singularidad. Y lo más importante de todo es que la inteligencia que surgirá continuará formando parte de la civilización humana, que ya es una civilización humano-máquina. En otras palabras, las máquinas futuras serán humanas aunque no sean biológicas ${ }^{12}$.

Kurzweil podría replicar a mis reproches que no se trata de degradar a los humanos, sino de dignificar a las máquinas. En realidad, está convencido de que ya somos máquinas, y no de calidad excelsa. Por eso no le cuesta creer que las que se construyan dentro de poco nos sobrepasarán en todos los frentes. Para él, lo que nos espera no es el superhombre, sino la supermáquina. El Aquiles maquinífero superará a la tortuga humana y además asumirá nuestra identidad como supremo gesto de... ¿̇benevolencia? Dado que no podríamos vencerlo si eligiésemos retarlo, no nos queda otra que unirnos a él hasta confundirnos en una entidad mixta supuestamente inmortal.

De todas las inverosimitudes del transhumanismo, esta es la mayor. No que llegue el día en que sepamos construir máquinas que piensen y que en definitiva sean humanas, sino que, siendo presuntamente capaces de semejante gesta, no haya en nuestro interior más hondo ni un solo átomo que categóricamente nos diferencie de ellas. Kurzweil y todos los demás transhumanistas son, por supuesto, incapaces de acreditar el equiparamiento. Se trata de una suposición, de una fe. Y una vez más, hay que reconocerle la virtud de la sinceridad:

Esta es la historia que quiero contar en este libro. La historia se fundamenta en la idea de que tenemos la capacidad de comprender nuestra propia inteligencia (penetrar en nuestro propio código fuente, si se prefiere), modificarla y ampliarla $^{13}$.

${ }^{12}$ Kurzweil, La singularidad está cerca, p. 33.

${ }^{13}$ Kurzweil, La singularidad está cerca, p. 4. 
El código fuente constituye el abc, la secuencia básica de instrucciones que inicia la andadura de un programa informático. Precisamente porque está al principio de todo lo que ese programa puede hacer, suponer que sea capaz de tomar posesión de sí para dar lugar a un proceso de automejora es más o menos como dar crédito al barón de Münchhausen cuando afirmó haber salido del pantano en que había caído tirando de su propia coleta. No hay máquina — por sublime que la imaginemos_ capaz de cuestionar las órdenes que le da su ser. Por eso resulta radicalmente insuficiente para convertirse en un yo: es y será siempre una cosa, un ello, un algoritmo que puede a lo sumo echar los dados al azar. El hombre tiene en lo más profundo de sí algo que no es un algoritmo, más bien es un hueco, un vacío, pero sin embargo posee la aptitud de contemplar su propia indigencia y buscar en otra parte que en sí mismo al que ha de redimirle de ella. Por eso su futuro no está en manos de ninguna revolución científico-tecnológica venida o por venir: está en la lucha agónica de su conciencia cuando busca dentro de sí y en las otras conciencias, tal vez en una que pueda escribirse con mayúsculas. Y justamente es a eso mismo a lo que llamamos, los que no somos transhumanistas, libertad.

Juan Arana

jarana@us.es 